\title{
Undercutting of Defects in Thin Film Protective Coatings on Polymer Surfaces Exposed to Atomic Oxygen
}

Sharon K. Rutledge

Lewis Research Center

Cleveland, Ohio

and

Judith A. Mihelcic

Cleveland State University

Cleveland, Ohio

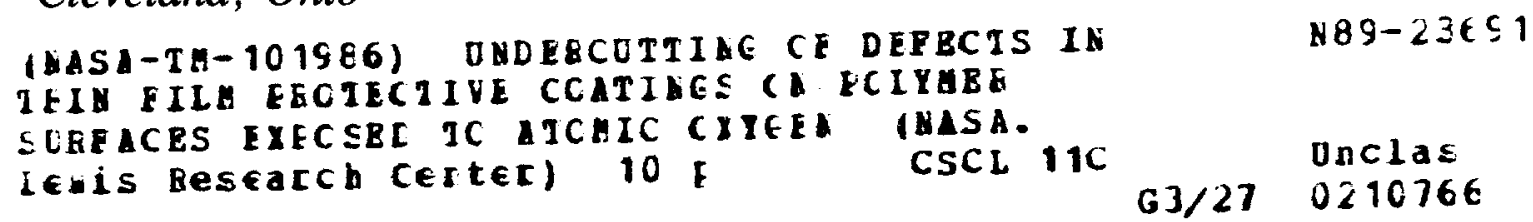

Prepared for the

16th International Conference on Metallurgical Coatings

sponsored by the American Vacuum Society

San Diego, California, April 17-21, 1989

\section{N/Sก}


Trade names or manufacturers' names are used in this report for idenification only. This usage does not constitute an official endorsement, either expressed or implied, by the National Aeronautics and Space Administration. 


\title{
UNDERCUTIING OF DEFECTS IN THIN FILM PROTECTIVE COATINGS ON POLYMER SURFACES EXPOSED TO ATOMIC OXYGEN
}

\author{
Sharon K. Rutledge \\ National Aeronautics and Space Administration \\ Lewis Research Center \\ Cleveland, Ohio 44135 \\ and \\ Judith A. Mihelcic \\ Cleveland State University \\ Cleveland, Ohio 44115
}

\begin{abstract}
SUMMARY
Protection for polymeric surfaces is needed to make them durable in the low Earth orbital environment, where oxidation by atomic oxygen is the predominant failure mechanism. Thin film coatings of oxides such as silicon dioxide are viable candidates to provide this protection, but concern has been voiced over the ability of these coatings to protect when defects are present in the coating due to surface anomalies occurring during the deposition process, handling, or micrometeoroid and debris bombardment in low Earth orbit. When a defected coating protecting a polymer substrate is exposed to atomic oxygen, the defect provides a pathway to the underlying polymer allowing oxidation and subsequent undercutting to occur. Defect undercutting was studied for sputter deposited coatings of silicon dioxide on polyimide Kapton. Preliminary results indicate that undercutting may be limited as long as the coating remains intact with the substrate. Therefore, coatings may not need to be defect free to give protection to the underlying surface.
\end{abstract}

\section{INTRODUCTION}

In low Earth orbit (LEO) between altitudes of 180 and $650 \mathrm{~km}$, single, neutral oxygen atoms in the ground state are the most predominant species (ref. 1). These atoms impact spacecraft surfaces with energies between 4.2 and $4.6 \mathrm{eV}$ due to the movement of the spacecraft through the environment (ref. 2). Many materials including polyimide Kapton are oxidized in LEO by the reactive atomic oxygen (ref. 2). The flexible solar array blanket for space Station Freedom which acts as a support for the solar cells and cell interconnects is composed of this polyimide (ref. 3). Based on Kapton erosion yields on shuttle flight experiment STS-8, it is estimated that the blanket would undergo structural failure due to material loss in approximately 0.5 years if the blanket were not protected (ref. 4), while the desired life for the Space station Freedom array is 15 years. The most promising protection technique to date is the application of a thin film coating (approximately 500 to $2000 \AA$ ) of a metal oxide such as $\mathrm{SiO}_{2}$ to the surface which acts as a barrier to the atomic oxygen, remains somewhat flexible and transparent, and allows the bulk properties of the underlying polyimide to be maintained (ref. 2 ). One of the major concerns about using a protective coating is the possibility of coating failure due to defects generated in the coating during the coating 
deposition or array manufacturing process, or during space flight by micrometeoroid and debris impact (ref. 5). These defects, usually in the form of pinholes or scratches, are sites where no coating exists to protect the underlying surface. Upon exposure to the LEO environment, the underlying material would be oxidized by atomic oxygen thus creating a void underneath the coating. Of concern is the degree to which the oxidation can spread transversely, undercutting beyond the initial site of the defect. If undercutting continues through atomic oxygen collisional and reactive processes or by growth of the size of the inital defect, then the removal of Kapton may result in structural failure of the array blanket. Also of concern is whether undercutting observed in ground based atomic oxygen simulation systems would be similar to that observed in space. This paper addresses these concerns by determining the extent undercutting occurs at defect sites due to oxidation by atomic oxygen, and whether the directionality of the atomic oxygen entering the defect plays a role in the extent of undercutting.

\section{EXPERIMENTAL APPARATUS AND PROCELUURE}

Protective coatings and substrates. - All of the materials evaluated in this paper consisted of sillcon dioxide ion beam sputter deposited onto ion beam sputter cleaned Kapton type $H N$ with a $1000 \mathrm{eV}$ Ar ion beam in an Ion Tech dual ion beam system. Pressure during deposition was approximately $10^{-4}$ torr. Film thickness was approximately 600 \& as measured by a stylus surface profiler (Sloan Dektak IIA). Although much of the data for Kapton obtained in space was for type $H$, type $H$ and $H N$ of the same thickness have very similar erosion yields based on observed mass loss rates in plasma ashers $\left(1.26 \times 10^{-8} \pm 6 \times 10^{-10}\right.$ and $1.37 \times 10^{-8} \pm 6 \times 10^{-10} \mathrm{~g} /\left(\mathrm{cm}^{2}-\mathrm{sec}\right)$ respective $\left.1 \mathrm{y}\right)$.

Scanning electron microscopy sample preparation. - The $\mathrm{SiO}_{2}$ coated Kapton samples were mounted to quartz optical flats with double stick Kapton tape, then a thin film coating of approximately 200 to $300 \AA$ of gold or platinum was applied over the coated surface so that the surface would be conductive enough to be viewed by scanning electron microscopy (Cambridge stereoscan 200). The conductive coating was applied prior to atomic oxyger exposure.

Atomic oxygen simulation. - Two different facilities were used to expose samples to atomic oxygen for testing. A plasma asher (SPI Plasma Prep II), which generated a $13.55 \mathrm{MHz}$ RF discharge of air in a partial vacuum (19 to 100 mtorr), was used to produce a plasma containing oxygen and nitrogen ions and atoms in various states. The nitrogen species in the plasma appear to have a negligible effect on the mass loss rate of materials exposed in the plasma as determined in previous experiments (ref. 4). The asher is extremely useful in providing qualitative indication of material survivability. Materials which survive in the asher have been found to survive in LEO. Plasma ashers ailow accelerated testing to be performed because they present a much more severe environment due largely to a higher oxygen atom arrival rate. The arriral of the oxygen species to the surface of a material in the asher is from random directions while in space, a directed sweeping arrival would occur due to the rotation of the solar array to track the sun.

A directed beam of oxygen ions was produced by mean: of an end Hall ion source (Commonwealth Scientific Inc.). Oxygen jons at an energy of approximately $57 \mathrm{eV}$ at a flux of approximately $8.5 \times 10^{16}$ atoms $/\left(\mathrm{cm}^{2}\right.$ - sec) were used to expose the samples in a racuum chamber whose pressure was $10^{-4}$ torr during 
operation with a base pressure of $10^{-6}$ torr. The beam was a mixture of $0^{+}$and $\mathrm{O}_{2}{ }^{+}$. The samples were located approximately $25 \mathrm{~cm}$ downstream of the ion source on a water cooled sample holder. A water cooled shield between the cathode filament and the samples was used to reduce the heat arriving at the samples from the filament. This source was used in conjunction with the asher to determine the role of atomic oxygen arrival directionality and energy on undercutting.

\section{RESULTS AND DISCUSSION}

Determining the extent of undercutting. - The amount of undercutting, at defect sites formed during the deposition process, as a function of time was studied by exposing a sample of $\mathrm{SiO}_{2}$ coated Kapton in a plasma asher and removing it at selected time intervals for observation in a scanning electron microscope. Figure 1 contains a series of photomicrographs of a selected area on the coated surface as a function of the effective fluence (based on Kapton mass loss/area and an erosion yield of $3 \times 10^{-24} \mathrm{~cm} / \mathrm{atom}$ ) incident upon the sample surface in the plasma asher. The light or dark ring surrounding each defect indicates the extent of coating undercutting. This is visible due to charging of the coating surface in the electron beam at points where the coating is no longer in contact with the underlying substrate when the electron beam energy is high enough. By measuring the distance between the center of the defect and the average edge of the undercutting ring, a plot of the undercutting extent versus atomic oxygen fluence could be made ( $f i g .2$ ). The plots indicate a slow initial growth in the undercutting radius which passes through a maximum before slowing to near zero growth after an effective atomic oxygen fluence of approximately $1 \times 10^{21}$ atoms $/ \mathrm{cm}^{2}$ for this sample. The photomicrographs appear to show the coating collapsing into the undercut area which could account for the reduction in the growth of the undercutting radius. These types of growth data, however, have been observed for defects which remain open through the duration of the atomic oxygen exposure.

Curve shape may be driven by several factors. Only about 11 percent of the atomic oxygen which lands on a carbon surface in LEO undergoes a chemical reaction with the surface, the remainder is scattered (ref. 6). Scattering is believed to occur in almost a cosine distribution from the surface (ref. 7 ). The reaction probability is believed to be energy dependent, with more energetic atoms having a higher reaction probability than those at lower energy (ref. 8). Also since these measurements are made for a two-dimensional surface, the extent of the depth of oxidation into the substrate is not observed, but could account for the initial increasing slope of the undercutting radius curves. A combination of these factors could provide a possible explanation for the growth and cessation of undercutting observed for these samples ( $f$ ig. 3). Initially, the opening in the coating would allow the polymer exposed by the defect to be oxidized but little undercutting would be observed because the material near the surface must be removed to a level where scattering of atomic oxygen under the coating could take place. Once this occurs, the rate of undercutting would increase. Some of the atomic oxygen will be scattered back out of the opening, and the probability of this would increase with the size of the coating defect, so for large defects it would be expected that smaller undercutting radii with respect to the size of the defect would be seen with exposure time. As time progresses, the atomic oxygen would have 
to undergo multiple scattering off of the polymer surface and the underside of the coating in order to allow the undercut region to grow outward. The farther it extends, the less likely it will be for the atomic oxygen to arrive at that point, without having undergone reaction, reassociation, or loss out of the defect. More testing is needed at higher atomic oxygen fluence levels to determine the extent of oxidation depth and whether undercutting does terminate as initial testing indicates. Modeling is needed in order to determine which factors are important.

For this sample of coated Kapton, out of approximately 113,800 defects $/ \mathrm{cm}^{2}$ visible on the surface, about 21,800 actually showed signs of undercutting. This means that a visual observation of a coated surface is not enough to determine if the coating has atomic oxygen pathways to the kapton surface; it must be subjected to an atomic oxygen environment. In low Earth orbit, the micrometeoroid environment has been predicted by the $1987 \mathrm{micrometeoroid} \mathrm{model}$ to provide approximately $1 \mathrm{hit} / \mathrm{cm}^{2}$ over 15 years for $10^{-12} \mathrm{~g}$ or larger particles (ref. 5). Debris is predicted to provide less than $1000 \mathrm{hits} / \mathrm{cm}^{2}$ over 15 years. The two combined represent approximately 20 times fewer oxidizable defects than are produced by coating and handling. Defects that can occur on the ground seem to be a greater problem, more worthy of addressing.

If intrinsic stresses in the protective coating cause the coating to tear due to lack of support in the area of the undercutting, then one could expect to see a continued growth in the undercut radius (ref. 9). Figure 4 shows an example of a reactively magnetron sputter deposited coating of silicon dioxide on kapton that does not continue to protect because the coating has torn as the undercutting progressed allowing more of the underlying surface to be exposed.

This can lead to total failure of the protective coating. Deposition of a low stress or adherent coating is needed to prevent this.

Energetic directed versus a thermal random oriented atomic oxygen arrival. - In the plasma of the asher, the atomic oxygen arrives with low energy $(0.1 \mathrm{eV})$ from many different angles while in space the arrival is closer to a rotated, directed beam at higher energy $(4.2$ to $4.6 \mathrm{eV})$. To bound the degree of undercutting one might expect in LEO, data from the plasma asher was compared to that from a $57 \mathrm{eV}$ directed oxygen ion beam exposure. The energetic ions would be expected to have a higher first impact reaction probability than in the plasma asher or LEO. Thus one could expect less undercutting, but deeper erosion of the kapton at the site of the defect. Samples of the $\mathrm{SiO}_{2}$ coated kapton were exposed to atomic oxygen in the plasma asher and the directed beam for an equivalent fluence of $1.5 \times 10^{2} 1$ atoms $/ \mathrm{cm}^{2}$ and $1.2 \times 10^{21}$ atoms $/ \mathrm{cm}^{2}$ respectively which corresponds to almost 1 yr in the space station Freedom constant density orbit (ref. 10). Figure 5 contains the photomicrographs of these samples after exposure. Although undercutting is present for the sample exposed in the energetic directed beam (fig. $5(\mathrm{~b})$ ), the extent of undercutting in comparison to the size of the defect is smaller than for the plasina asher exposed defects. This is illustrated in figure 6 . In general, the radius of undercutting compared to the defect size is smaller for larger defects in both cases as would be expected. A directed atomic oxygen beam rotating around a surface, which is closer to the arrival in LEO, would tend to produce more undercutting than a fixed directed beam. 


\section{CONCLUSIONS}

Tests to date have shown that the growth of undercutting appears to be limited with atomic oxygen exposure on coated polyimide surfaces in which the protective coating stays in contact with the substrate. Therefore, the production of defect free coatings, although desirable, is not as important as the ability of the coating to remain intact as undercutting occurs. Thus deposition of low intrinsic stress, tear resistant films may be critical to long term durability in LEO. Large defects do not produce proportionately large areas of undercutting, therefore size should not cause great concern provided the defects are not long and interconnecting which could provide a structurally weak point. Methods of ground evaluation for defects should involve the testing of coupons of the coated material with ground based atomic oxygen plasma devices in order to accurately determine the number of defects produced. The number of defects on the surface produced in the coating process and the mechanical integrity of the coating, are quality control issues extremely pertinent to the survival of polymers to be used on Space station Freedom and for other LEO space systems if long term durability against attack by atomic oxygen is to be achieved.

\section{REFERENCES}

1. United States Committee on Extension to the Standard Atmosphere, U.S. Standard Atmosphere, 1976 (U.S. Gov't Print. Off., Washington, D.C., 1976).

2. B.A. Banks, M.J. Mirtich, S.K. Rutledge, and H.K. Nahra, Proceedings 18th Photovoltaic Specialists Conference, Las Vegas, NV, p. 381 (IEEE, New York, 1985).

3. C.R. Baraona, "The Space Station Power System," Fifth Conference on Photovoltaic Generators in Space, Noordwijk, Netherlands, 1986 (also available as NASA TM-88847).

4. S.K. Rutledge, B.A. Banks, F. DiFilippo, J. Brady, T. Dever, and D. Hotes, "An Evaluation of Candidate Oxidation Resistant Materials for Space Applications in LEO," Workshop on Atomic Oxygen Effects, Pasadena, CA, (NASA TM-100122), 1986.

5. M.J. Mirtich, H. Mark, and W.R. Kerslake, "The Effect of the Near Earth Micrometeoroid Environment on a Highly Reflective Mirror Surface, "NASA TM- $101307,1988$.

6. C.K. Purvis, D.C. Ferguson, D.B. Snyder, N.T. Grier, J.V. Staskus, and J.C. Roche, "Environmental Interactions Considerations for Space Station and Solar Array Design," Preliminary Report, July 1985.

7. J.C. Gregory, "Interaction of Hyperthermal Atoms on Surfaces in Orbit: The University of Alabama Experiment," Proceedings of the NASA Workshop on Atomic Oxygen Effects -- Low Earth Orbital Environment, (NASA CR-181163), pp. 29-36, 1986.

8. D.C. Ferguson, "The Energy Dependence and Surface Morphology of Kapton Degradation Under Atomic Oxygen Bombardment," Thirteenth Space Simulation Conference. The Payload: Testing for Success, edited by J. Stecher, NASA CP-2340, pp. 205-221, 1984. 
9. B. Banks and S. Rutledge, "Low Earth Orbital Atomic Oxygen Simulation for Materials Durability Evaluation," Proceedings of the 4 th International Symposium on Spacecraft in the Space Environment. Toulouse, France, Sept. 6-9, 1988.

10. L. Leger, J. Visentine, and B. Santos-Mason, "Selected Materials Issues Associated with Space Station," SAMPE Quarterly, 8, pp. 48-54 (1987).

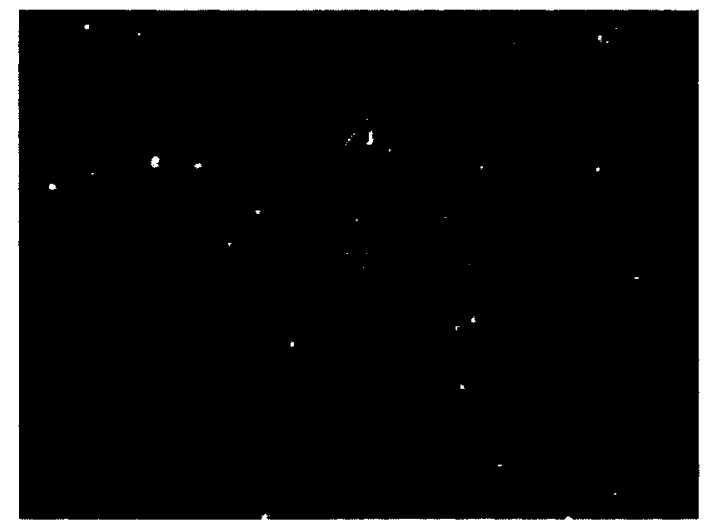

(A) $2.95 \times 10^{20} \mathrm{ATOMS} / \mathrm{cm}^{2}$.

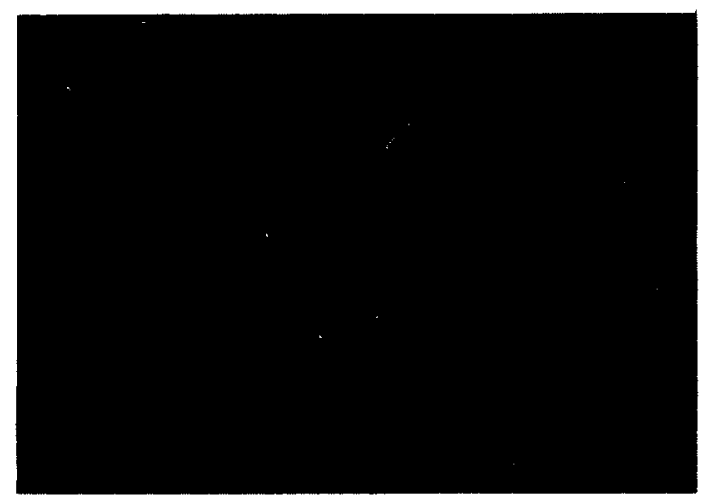

(C) $1.0 \times 10^{21} \mathrm{AIOMS} / \mathrm{CM}^{2}$.

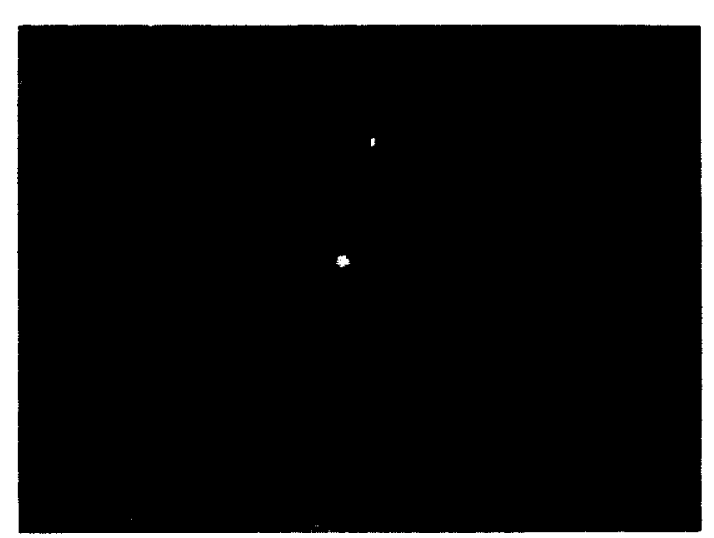

(B) $4.6 \times 10^{20} \mathrm{AlOMS} / \mathrm{cm}^{2}$.

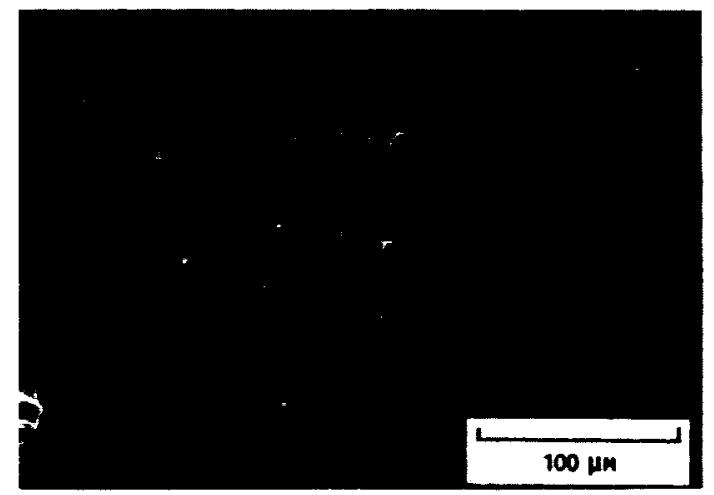

(D) $1.57 \times 10^{21} \mathrm{AIOMS} / \mathrm{cm}^{2}$.

FIGURE 1. - SCANMING ELECTRON PHOTOMICROGRAPHS OF SILICON DIOXIDE COATED KAPTON EXPOSED IN AN ATOMIC OXYGEN PLASMA ASHER AT VARIOUS FIUENCE. LIVELS.

ORIGINAL PAGE IS

OF POOR QUALITY 

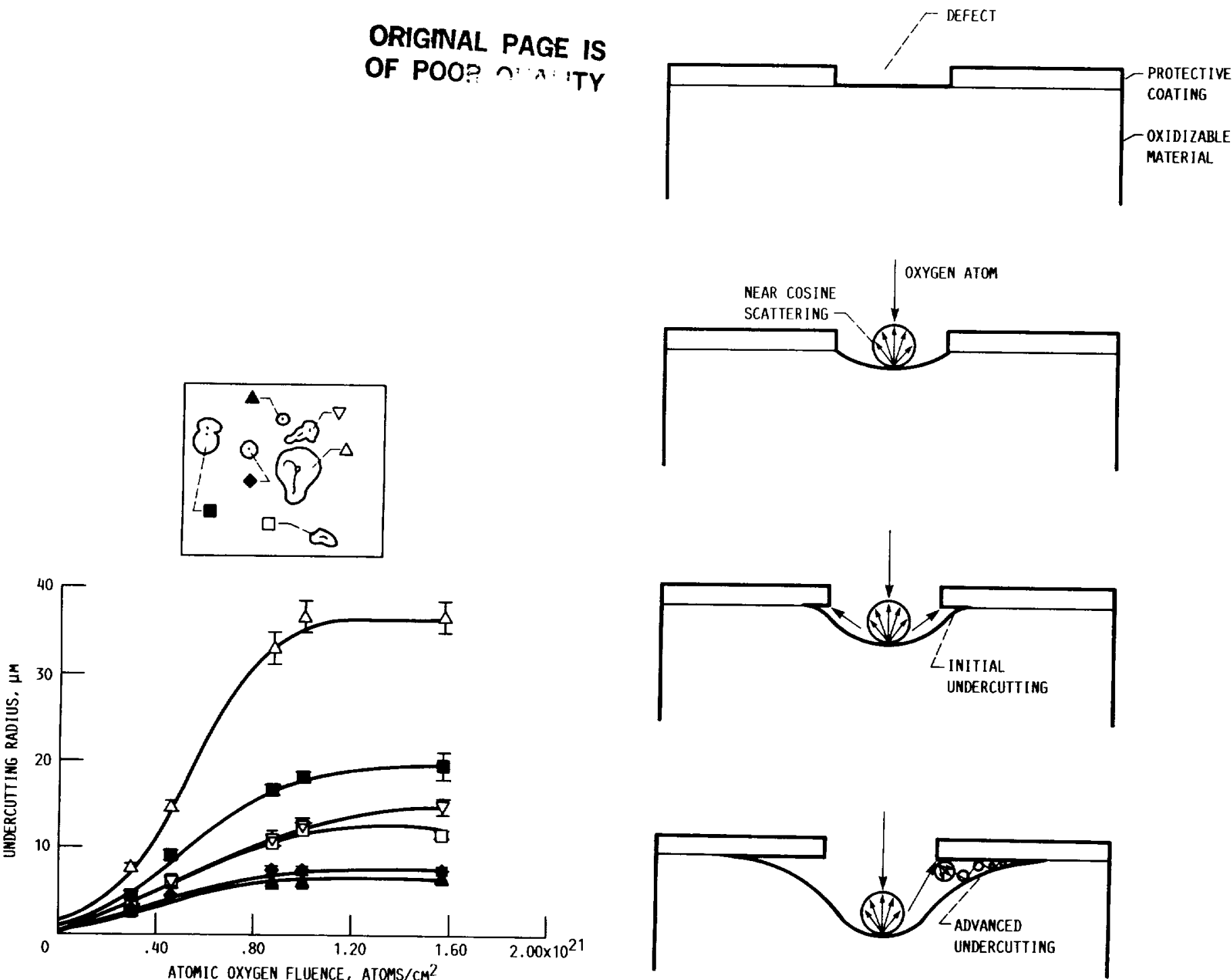

FIGURE 2. - UNDERCUTIING EXTENT OF DEFECTS ON SILICON DIOXIDE COATED KAPTON AS A FUNCIION OF ATOMIC OXYGEN FLUEMCE DURING EXPOSURE IN A PLASMA ENVIRONMENT.

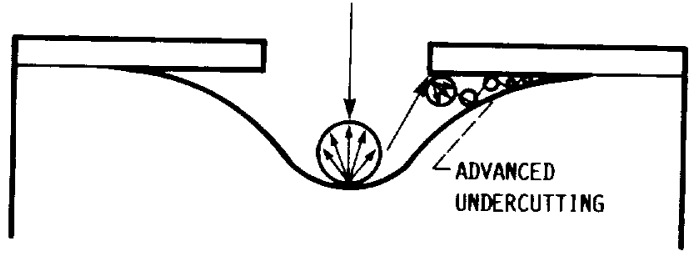

FIGURE 3. - POSSIBLE SCENAR IO FOR UNDERCUTTING OF A DEFECTED COATING IN AN ATOMIC OXYGEN ENVIRONMENT.

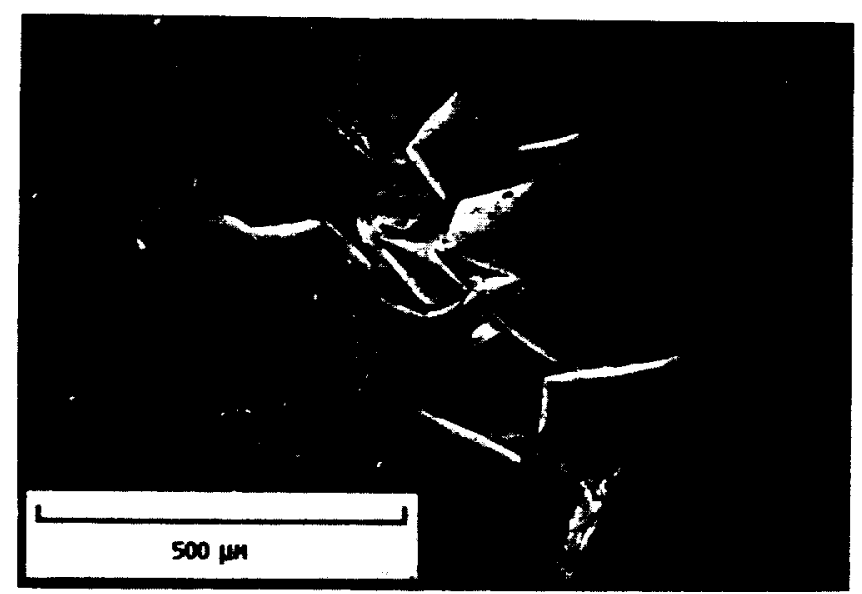

FIGURE 4. - REACTIVE MAGNETRON SPUTTER DEPOSITED SILICON DIOXIDE ON KAPTON AFTER EXPOSURE TO AN EQUIVALENT ATOMIC OXYGEN FLUENCE OF APPROXIMATELY $10^{22}$ ATOMS $/ \mathrm{cm}^{2}$. 
ORIGINAL PAGE IS OF POOR QUALITY

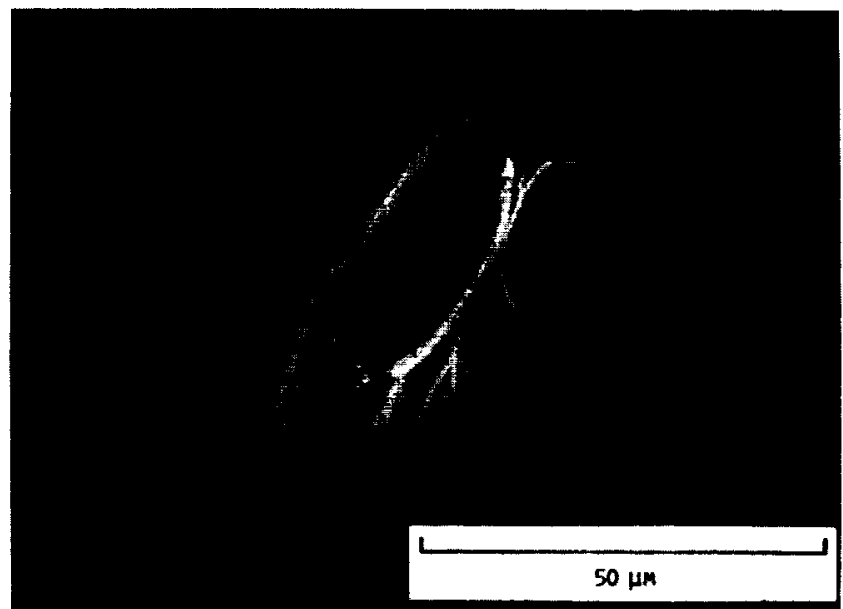

(A) PLASMA ASHER EFFECTIVE FIUENCE of $1.5 \times 10^{21} \mathrm{ATOMS} / \mathrm{cm}^{2}$.

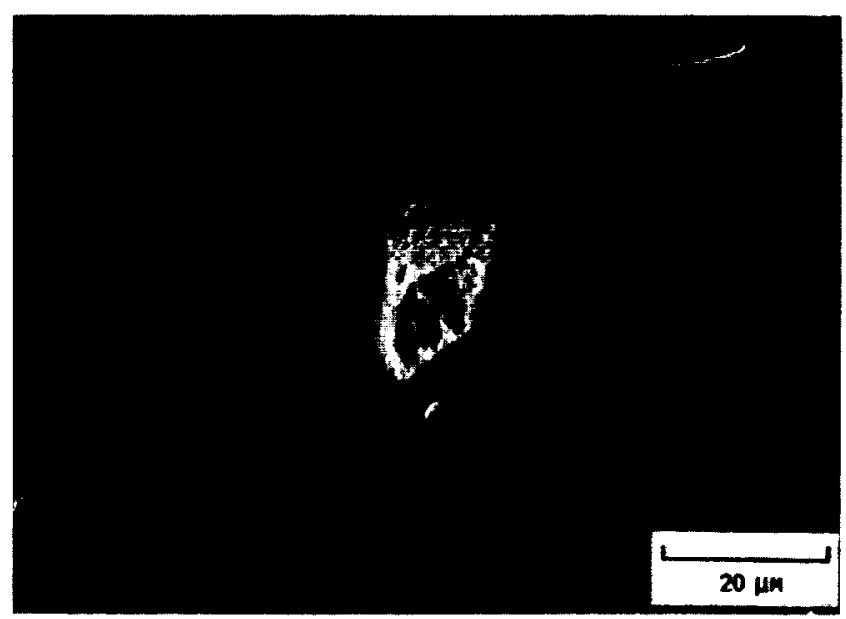

(B) DIRECTED BEAM EFFECTIVE FLUENCE OF $1.2 \times 10^{21} \mathrm{AIOMS} / \mathrm{Cm}^{2}$.

FIGURE 5. - PHOTOMICROGRAPHS OF SILICON DIOXIDE COATED KAPTON AFTER EXPOSURE TO ATOMIC OXYGEN.

RU = UNDERCUTTING RAOIUS;

RD = DEFECT RADIUS

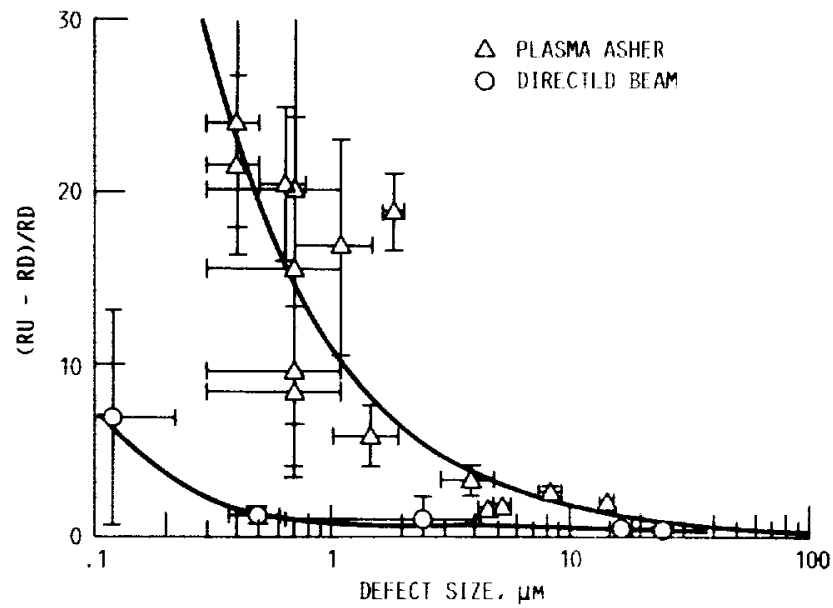

FIGURE 6. - EXTENT OF UNDERCUIIING IN COMPARISON TO THE ORIGINAL DEFECT SIZE FOR PI ASMA ASHER [XPOSFD AND DIRECIED BEAM EXPOSED SILICON DIOXIIF COAIT.D KAPION. 


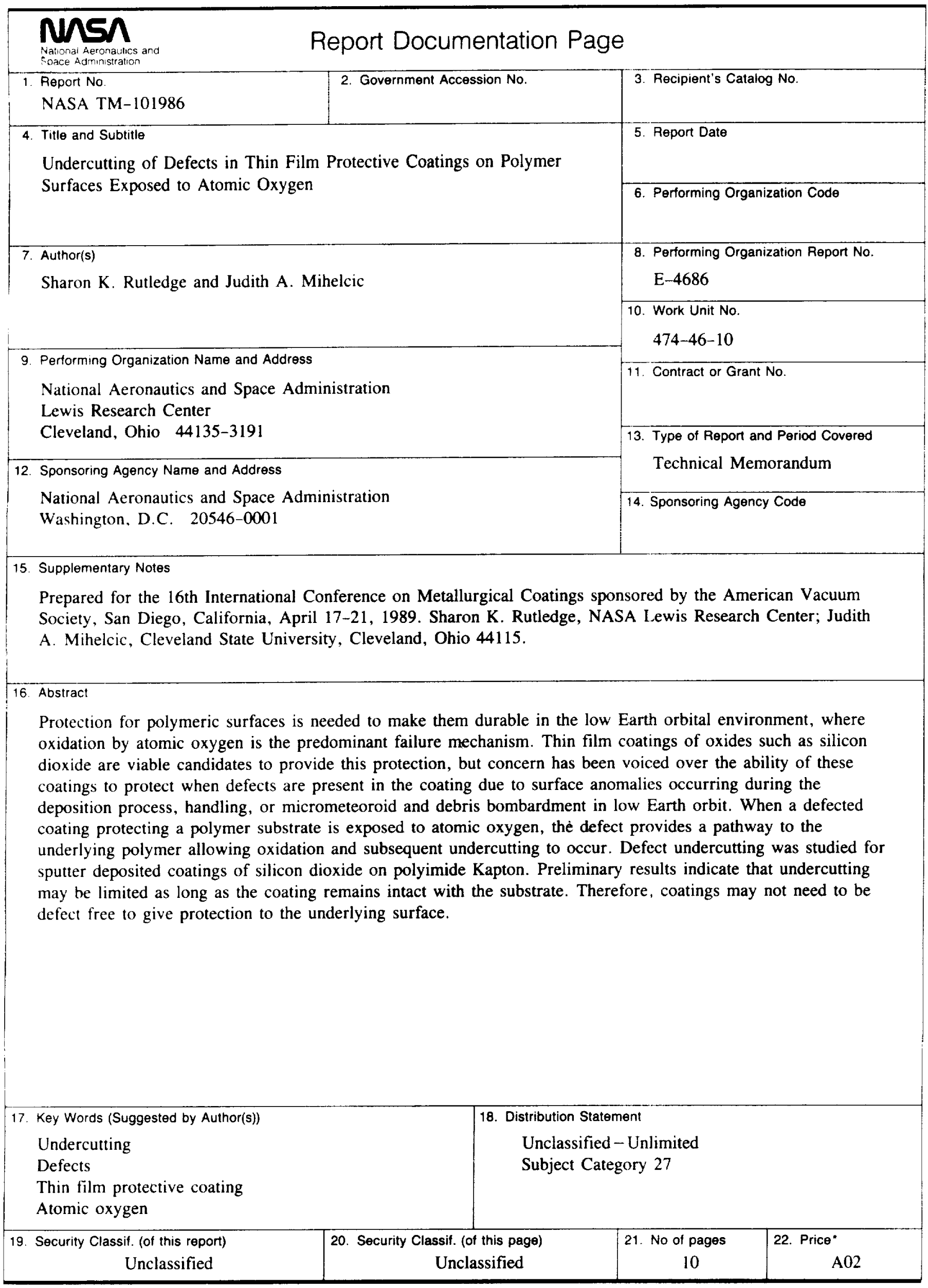

